\section{$\underset{\substack{\text { hommes } \\ \text { \& migrations }}}{ }$}

\section{Hommes \& migrations}

Revue française de référence sur les dynamiques

migratoires

$1280 \mid 2009$

Les Turcs en France : quels ancrages?

\title{
Des individus aux institutions
}

L'islam au sein des diasporas turques en Europe

\section{Ayhan Kaya}

Traducteur : Angie Cotte

\section{(2) OpenEdition \\ Journals}

\section{Édition électronique}

URL : http://journals.openedition.org/hommesmigrations/301

DOI : 10.4000/hommesmigrations.301

ISSN : 2262-3353

\section{Éditeur}

Musée national de l'histoire de l'immigration

\section{Édition imprimée}

Date de publication : 1 juillet 2009

Pagination : 62-77

ISSN : 1142-852X

Référence électronique

Ayhan Kaya, " Des individus aux institutions », Hommes \& migrations [En ligne], 1280 | 2009, mis en

ligne le 29 mai 2013, consulté le 20 avril 2019. URL : http://journals.openedition.org/

hommesmigrations/301; DOI : 10.4000/hommesmigrations.301 


\section{Des individus aux institutions}

L'islam au sein des diasporas turques en Europe

Par le professeur Dr. Ayhan Kaya, Institut européen, université d'Istanbul Bilgi

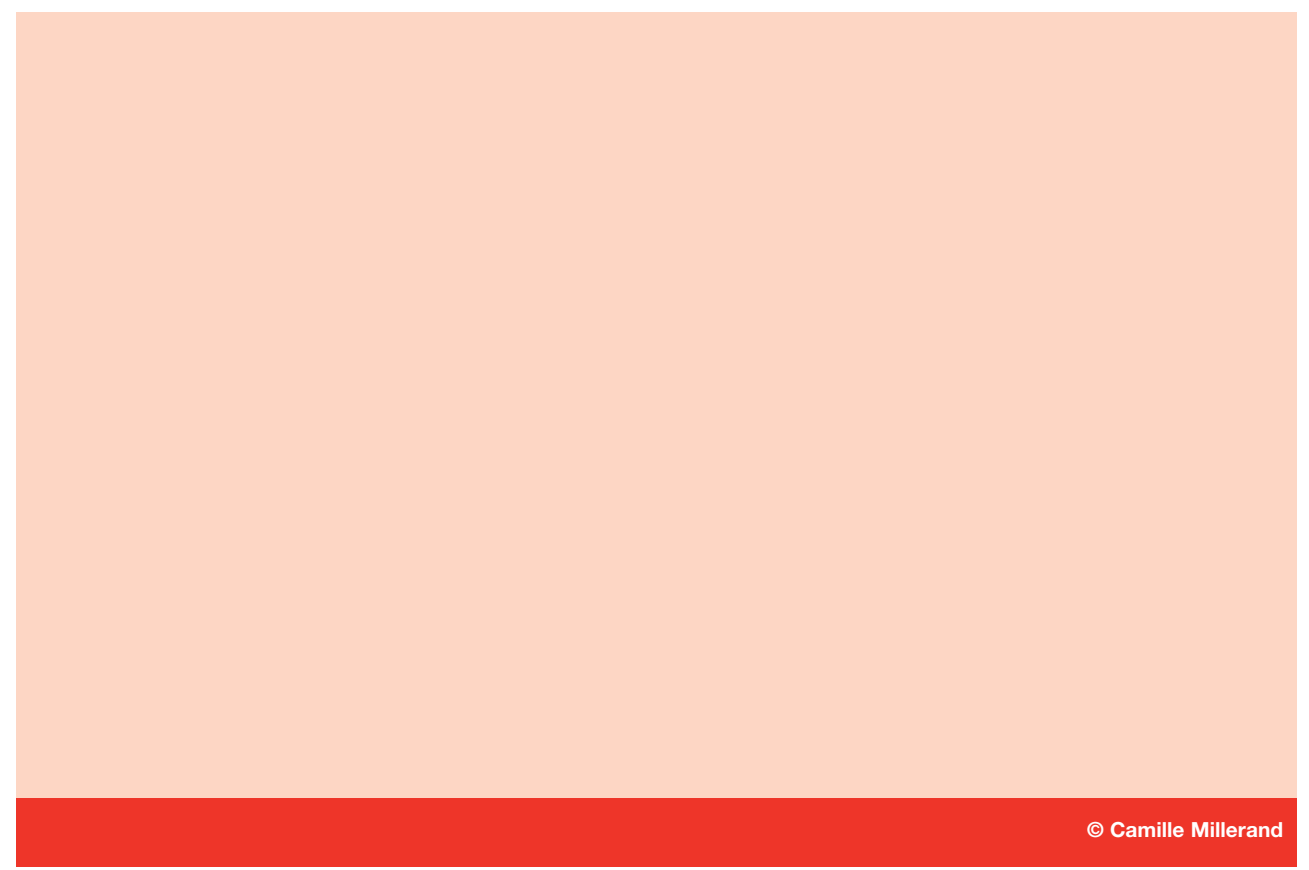

En Europe, les relations que les immigrés turcs entretiennent avec l'islam suscitent de nombreuses interrogations. Repère culturel essentiel dans la construction d'identités en migration ? Choix idéologique et politique en réponse à la pression des institutions de pays laïques ? La religion musulmane se présente également chez les jeunes générations comme un levier paradoxal d'intégration. Pour apprécier la diversité des rapports entre des individus, une religion et des institutions, cette analyse compare la situation des Euro-Turcs en Allemagne, en France, en Belgique et aux Pays-Bas. 
Plus de 4,5 millions d'Euro-Turcs habitent dans les pays de l'Union européenne : environ 3 millions en Allemagne, 400000 en France, 400000 aux Pays-Bas et 200000 en Belgique. Les immigrés tendent généralement à se conformer aux structures légales, politiques, sociales et économiques du pays dans lequel ils habitent. C'est pourquoi il n'est pas possible d'envisager que les immigrés venant d'un pays d'origine spécifique, dispersés dans plusieurs pays de destination, génèrent des stratégies de participation politique similaires. Ce que je souhaite à travers l'analyse suivante $^{(1)}$, c'est examiner la façon dont les Euro-Turcs qui vivent en Allemagne, en France, en Belgique et aux Pays-Bas répondent au changement de la perception de l'immigration et de l'islam en Occident. Car il est possible de jouer de ses identités multiples avec succès, comme en témoigne cette jeune Française turque voilée : "Lorsque jétais enfant, je me sentais plutôt Turque, bien que mon entourage soit français. En grandissant, mon identité française est devenue plus visible en public. Plus récemment, jai découvert une autre facette de mon identité, soit l'islam. J'ai une triple identité maintenant. C'est bien, car je peux vivre avec les trois identités ; je n'ai pas besoin de choisir.)",

Les communautés d'immigrés sont différentes les unes des autres dans leur façon de construire leurs identités. Alors que les Français turcs développent un discours identitaire universaliste, républicain et laïc,

En Belgique, si les Flamands turcs tendent à adopter une identité culturelle plus distincte de la société d'accueil, les Wallons turcs s'assimilent davantage à la culture wallonne. les Allemands turcs génèrent un discours politique plus déterminé, culturaliste et religieux. Les raisons de cette différence s'expliquent par les contextes historique, politique et économique de chaque pays. L'Allemagne et les Pays-Bas ont un régime d'intégration culturaliste et différentialiste. La France a mis en place un régime universaliste et assimilationniste, nuancé d'un brin de multiculturalisme. En Belgique, si les Flamands turcs tendent à adopter une identité culturelle plus distincte de la société d'accueil, les Wallons turcs s'assimilent davantage à la culture wallonne. En effet, la société flamande est plus encline à un discours multiculturaliste d'intégration comme aux Pays-Bas, alors que les Wallons sont plus enclins au discours assimilationniste.

Cependant, tous ces pays sont maintenant très critiqués sur la manière dont l'élite politique et les médias dominants cadrent les immigrés et les musulmans. Le communautarisme dans l'Allemagne actuelle et les Pays-Bas semble apporter aux Allemands turcs et aux Néerlandais turcs un terrain plus libéral qui leur permet de s'intégrer politiquement, socialement et économiquement dans la société dominante. Les données récoltées lors des interviews, structurées et approfondies 
dans le cadre de la recherche "Euro-Turcs"(3), indiquent qu'Allemands turcs, Néerlandais turcs et Flamands turcs sont généralement plus communautaristes, religieux et conservateurs que les Français turcs ou les Wallons turcs. En comparaison, les Allemands turcs, contrairement aux Français turcs ou aux Wallons turcs, semblent être moins favorables à l'intégration culturelle et plutôt satisfaits de leurs enclaves ethniques, archipels religieux et réseaux de solidarité traditionnels. Selon d'autres résultats de la recherche, les Français turcs et les Wallons turcs semblent être plus engagés dans la vie moderne, s'orientant vers l'intégration, la langue française et le sécularisme, tout en étant moins engagés dans la vie politique et culturelle française ou belge. Les Allemands turcs, les Néerlandais turcs et les Flamands turcs semblent au contraire créer des identités plus cosmopolites, hybrides, globales et réflexives qui redéfinissent l'européanisme, cet état continuellement changeant. Ainsi, ces expériences semblent indiquer que l'islam ne contredit pas forcément l'européanisme, la modernité et la mondialisation.

\section{La participation politique des communautés d'immigrés}

Lorsque les membres de groupes exclus ou marginalisés sont opprimés à cause de leur adhésion et de leur différence ethnoculturelle, leur positionnement dans le monde n'est pas individuel mais devient une affaire collective. Ils résistent ou tombent ensemble. Cette condition collective pourrait indiquer la nécessité de concevoir une politique de redistribution des ressources et des opportunités individuelles, afin de les libérer des identités ou, en tout cas, des conditions qu'ils n'ont pas choisies ${ }^{(4)}$. L'Allemagne, les Pays-Bas et certaines parties de la Belgique sont devenus récemment des endroits propices pour l'engagement politique des immigrés au niveau local, national et parfois européen. Il ne faut pas sous-estimer la tendance des Euro-Turcs à devenir plus politiquement mobiles depuis la montée des tendances islamophobes en Occident. Les élections locales en Belgique et aux Pays-Bas en 2006 ont vu une participation de plusieurs milliers d'Euro-Turcs en tant que candidats et électeurs. Participer aux élections est devenu méritoire aux yeux des immigrés d'origine turque et de leurs descendants, car cela leur confère un statut plus solide dans la société.

Cependant, et contrairement à ce qui est communément admis, la recherche sur les Euro-Turcs révèle une corrélation positive entre l'adhésion ethnoculturelle des Euro-Turcs et leur participation dans la vie politique. Plus les réseaux associatifs sont denses, plus la confiance politique émerge et plus la participation dans 
la vie politique est grande. Les associations de bénévoles en Allemagne, en Belgique et aux Pays-Bas créent de la confiance sociale et une plus grande implication dans la vie politique ${ }^{(5)}$. De surcroitt, les médias ethniques contribuent aussi aux activités politiques des communautés d'immigrés dans la société élargie.

Il est évident que les régimes libéraux ont la préférence des immigrés et de leurs enfants. Mais les démocraties occidentales semblent échouer dans le traitement des revendications minoritaires de quête de justice. Kymlicka et Norman suggèrent que "les groupes d'immigrés qui se sentent aliénés de l'identité nationale et religieuse élargie seront vraisemblablement aliénés de l'arène politique ${ }^{(6)}$. La rhétorique traditionnelle sur la citoyenneté tend à favoriser les intérêts du groupe national dominant au détriment des immigrés. D'où l'impossibilité de la compréhension "classique" de la citoyenneté à résoudre les problèmes de coexistence d'entités "culturellement discrètes". Afin d'éviter le conflit et l'aliénation potentiels, une tâche essentielle doit être menée : les lois sur l'immigration ne doivent pas être basées sur des qualités culturelles, religieuses, linguistiques et ethniques prescrites.

Des lois relatives à la citoyenneté qui seraient modérées et démocratiques, en phase avec la tâche citée ci-dessus, seraient à même de dissoudre l'importance donnée par les groupes d'immigrés aux questions d'ethnicité, du religieux et de la nationalité. La croissance forte du taux de naturalisation des Allemands turcs après l'introduction de lois libérales en 2000 illustre sans équivoque ce phénomène, puisque les immigrés et leurs descendants répondent positivement aux politiques d'inclusion citoyennes. Les Turcs ayant acquis la citoyenneté allemande avant l'année 2000 étaient environ 350 000. Ils sont aujourd'hui 800 000. En d'autres termes, cela signifie que 60\% des Allemands turcs ont déjà la nationalité allemande ou ont le projet de l'obtenir rapidement. Ce pourcentage représente environ 2 millions de personnes sur un total de 3 millions d'Allemands turcs. La nouvelle réglementation sur la citoyenneté en Allemagne, bien qu'ayant ses limites, démontre que les immigrés sont réceptifs vis-àvis des politiques démocratiques d'inclusion et des changements réglementaires.

\section{La quête identitaire pose-t-elle un défi sécuritaire?}

Il y a une forte tendance actuellement dans les milieux des immigrés d'origine musulmane, ainsi que d'autres minorités ethnoculturelles en Occident, à raffiner ou parfaire ses identités, ses relations à l'ethnicité ou à la religion. Les sociétés dominantes ont tendance à interpréter ces quêtes identitaires comme étant le résultat d'un conservatisme et d'un essentialisme des musulmans en Europe, et des Euro-Turcs en 
particulier. La critique habituelle consiste à souligner que cet essentialisme ethnoculturel est un défi pour la sécurité nationale, sociétale et culturelle de la société majoritaire. Cependant, la recherche entreprise parmi les populations immigrées d'origine turque qui habitent dans les quatre pays étudiés (Allemagne, France, Belgique et PaysBas) démontre que cette renaissance ethnoculturelle parmi les Euro-Turcs peut être traduite comme une quête de justice et d'équité et non pas un défi sécuritaire.

Qu'en est-il de l'affirmation de plus en plus populaire consistant à proclamer que l'Union européenne subira une "arrivée" de migrants turcs lors de l'adhésion de la Turquie? J'affirme que cette revendication est construite de toutes pièces, que cette peur a été politiquement et socialement préfabriquée par une élite politique conservatrice qui n'a pas été capable de trouver les solutions aux problèmes structurels d'insécurité, de désindustrialisation, de pauvreté, de violence, d'inégalité politique et de gestion des étrangers. Il ne faut pas oublier que la même peur était dénoncée lorsque l'Espagne, le Portugal et la Grèce ont rejoint l'Union. À cette occasion, une migration inverse a eu lieu. 30 \% des Euro-Turcs indiquent qu'ils pourraient retourner en Turquie en cas d'adhésion à l'UE. Un autre aspect à prendre en considération 
est l'augmentation du nombre de citoyens de l'Union européenne qui achètent des propriétés en Turquie. En effet, la Turquie est devenue un choix de lieu de vie pour certains citoyens de l'UE et le nombre d'Euro-Turcs qualifiés de la jeune génération retournant en Turquie est en augmentation. Inanç Kutluer, directeur de l'Institut hollandais de migration, qui est un Euro-Turc, indique que chaque année environ 1000 jeunes Hollandais turcs, attirés par l'économie dynamique de la Turquie, retournent dans leur pays pour être employés dans des compagnies internationales ${ }^{(7)}$. 7,5\% des Allemands turcs, 10 \% des Français turcs et 6,8 \% des Belges turcs se définissent comme assez religieux, un pourcentage semblable aux Turcs en Turquie. On nous indique que 89 \% des Allemands turcs, 80 \% des Français turcs et 84 \% des Belges turcs sont assez croyants. Cependant, 2, 4 \% des Allemands turcs, 10 \% des Français turcs et 5,8\% des Belges turcs semblent être athées ou agnostiques. Ces chiffres contredisent les perceptions stéréotypées de l'islam à l'Ouest, enfermant les musulmans dans des représentations de fondamentalisme présumé. Récemment, des mouvements d'orientation islamique tels que Cojepiennes basé à Strasbourg, ou le Millî Görüs qui développe plutôt une vision nationaliste, ont montré leur détermination à adapter les modes de vie occidentaux à leurs propres identités. De telles interprétations modernes de l'islam prouvent que celui-ci ne constitue pas en réalité une menace pour les valeurs occidentales. Les résultats de la recherche "Euro-Turcs" indiquent que beaucoup d'Euro-Turcs s'identifient à de multiples identités, française, allemande, néerlandaise, tout en restant musulmans et Turcs. Ce qui est nouveau, c'est la position de l'identité politique qui précède l'identité religieuse et ethnique.

\section{L'individualisation de l'islam parmi les jeunes générations}

Les jeunes générations d'Euro-Turcs d'origine musulmane ont de plus en plus tendance à considérer la religion comme une quête spirituelle et intellectuelle qui leur offre la possibilité d'une distanciation face aux pratiques culturelles transmises par les communautés musulmanes. Nadia Fadil a mené une enquête auprès des jeunes marocains belges ${ }^{(8)}$ et a révélé que ces jeunes subissaient une forme d'émancipation qui leur permettait de récupérer leur foi individuelle vis-à-vis de l'autorité de la culture parentale. Les jeunes générations font la distinction entre islam et culture. Mandaville a aussi observé une tendance similaire, particulièrement parmi les jeunes femmes musulmanes en diaspora : "De plus en plus de femmes semblent prendre en charge leur religion musulmane. Elles la questionnent, la critiquent et rejettent même l'islam de leurs parents. Souvent ce processus entraîne une distinction entre la culture, qui 
aurait des effets oppressants dérivés des origines ethno-sociales des parents, et la religion, un vrai islam inaltéré par la culture ou la discrimination sexuelle ${ }^{(9)}$."

Les immigrées semblent percevoir l'islam comme une force progressiste qui les émancipe de leurs racines traditionnelles, tout en les préservant d'une soumission aux cultures occidentales. Jorgen Nielsen ${ }^{(10)}$ indique que les femmes musulmanes dans les diasporas ne se réfèrent plus aux codes vestimentaires, aux mariages arrangés et aux rôles homme/femme comme symboles de l'islam. L'intérêt semble se déplacer vers des valeurs spirituelles et éthiques de l'islam. Dans son étude sur les Norvégiens pakistanais, Mette Andersson révèle de la même manière que les jeunes Pakistanais dans les diasporas critiquent ouvertement la façon dont les parents utilisent "la religion comme un bouclier", masquant les pratiques culturelles d'oppression de la femme. Leur critique est dirigée vers les Pakistanais de la première génération qui pensent que le mariage forcé et les conditions d'inégalité homme/femme sont des prescriptions religieuses. Les jeunes pensent que l'analphabétisation est la "source principale de l'indifférence et du mélange des traditions religieuses et culturelles ${ }^{(1)}$ ". Andersson attire aussi notre attention sur le fait que ce sont les femmes, plus que les hommes, qui problématisent la relation entre culture et religion.

"Nous apprenions le contenu de l'islam de nos parents. Ils nous ont appris à prier, à jêेner, et à lire le Coran. Nous apprenions cela par habitude, sans connaître la signification des versets et des rites. Nos parents ne les connaissaient pas non plus. Seuls les imams connaissaient la signification des versets, car ils pouvaient comprendre l'arabe, la langue du Livre saint. Maintenant nous n'avons plus besoin des parents pour apprendre la religion. Nous avons Internet, les associations religieuses et les écoles pour satisfaire notre curiosité. Je ne souhaite que personne, qu'aucune institution comme la mosquée, m'impose quoi que ce soit concernant ma foi. Je surfe souvent sur Internet, et jenvoie mes écrits aux forums appropriés ${ }^{(2)}$." Ce sont les paroles d'une jeune Euro-Turque voilée qui perçoit l'islam comme une opportunité d'émancipation de la répression de sa culture parentale et des institutions traditionnelles. C'est ainsi que les jeunes utilisent les moyens de communication modernes fournis par le processus contemporain de mondialisation. Les médias et les technologies de l'information ont certainement joué un rôle important dans l'émergence d'une nouvelle vague d'intellectuels musulmans dont les activités représentent une forme de "mondialisation par le bas" contre-hégémonique et hybride. Brecher et al. ${ }^{(13)}$ définissent "la mondialisation par le bas" comme un enchevêtrement constitutif qui est devenu caractéristique des réseaux modernes de diasporas. L'expansion des réseaux économique, culturel et politique entre les Euro-Turcs et la Turquie est un exemple de cette tendance. 


\section{Une religion numérique au sein des diasporas virtuelles}

Le circuit mondial des télécommunications modernes contribue également à la formation d'une oumma numérique au sein de la diaspora musulmane ; l'idée d'une sorte de communauté des sentiments homogène, qui prend forme à l'intérieur d'un flux constant de signes et de messages identiques qui traversent le cyberespace. Une oumma numérique (communauté musulmane) façonnée par la mondialisation électronique a tendance à s'engager dans des formes variées de ijtihâd (mot arabe qui signifie effort de réflexion pour interpréter les textes fondateurs de l'islam), car chaque individu habite un contexte social, politique et culturel différent à l'intérieur de la diaspora. Alors que les signes et les messages disséminés à travers la diaspora sont plutôt homogènes, leur impact sur les vies individuelles est très différent. Les signes et messages forment une oumma plus hétérogène et individuelle. Cette forme d'ijtihâd, qui est construit par le biais des médias, a la capacité de transformer les récipiendaires en alim virtuels (mot arabe pour "intellectuels") qui peuvent défier l'autorité des savants religieux traditionnels ${ }^{(14)}$. Comme l'indique avec justesse Arjun Appadurai, "de nouvelles formes de communication transmises électroniquement créent actuellement des voisinages virtuels qui ne sont plus contenus par des frontières territoriales ${ }^{(15)}$ ". Ces nouvelles communautés de sentiments sont construites dans le cyberespace, un espace qui est souvent occupé par les sujets diasporiques modernes.

"Il est temps de reconnaître que les vrais enseignants de nos enfants ne sont pas des professeurs d'école ou des universitaires mais des cinéastes, des publicitaires et des fournisseurs de culture populaire. Disney fait plus que Duke, Spielberg impose plus que Stanford, MTV gagne sur MIT ${ }^{16)}$, , indique Benjamin R. Barber. Diana Crane a écrit, il y a plus de trente ans ${ }^{(17)}$, sur la manière dont la connaissance est produite par des collèges invisibles. Les jeunes n'apprennent pas seulement à l'intérieur du cursus scolaire, mais aussi par les cursus "non officiels" (c'est-à-dire, les films, la télé, l'Internet, les journaux en ligne, l'enseignement à distance, les librairies, les bibliothèques, les musées, les Compact Disc, les jeux vidéo et les bandes dessinées) ou à travers ce que Mahiri appelle la "pédagogie de la culture pop ${ }^{(18)}$ " et les ressources d'apprentissage populaire (centres communautaires, églises, mosquées et groupes de pairs). Cette pratique des jeunes contemporains à travers des collèges invisibles semble modifier leur relation vis-à-vis de l'enseignement scolaire traditionnel. Il est évident que les changements technologiques ont transformé les nouvelles générations. Les jeunes ont la possibilité d'identités multiples par voie électronique. Par exemple, les Belges musulmans turcs, ou kurdes, sont, en quelque sorte, des 
identités fabriquées et entretenues dans le circuit de télécommunication moderne. On pourrait aussi prétendre que les changements que traversent les jeunes générations de musulmans dans les médias affectent aussi les générations des aînés. Comme le rappelle Margaret Mead, nous sommes passés d'une culture post-figurative, dans laquelle les jeunes apprennent des aînés, à une culture co-figurative ${ }^{(19)}$, dans laquelle les enfants et les adultes apprennent de leurs pairs. La culture dans laquelle les jeunes se trouvent est tellement différente que les aînés ne peuvent pas les aider dans leur cheminement. Les jeunes ne sont plus cadrés par les séquences linéaires d'un médium écrit. Mead ajoute que, plus tard, nous vivrons probablement dans une culture pré-figurative dans laquelle les aînés apprendront des jeunes. Nous devons, indique Mead, découvrir les méthodes pré-figuratives d'enseignement et d'apprentissage qui maintiendront l'avenir ouvert pour que les enfants apprennent à apprendre et à découvrir la valeur de l'engagement, plutôt que de recevoir un enseignement de toutes pièces, couplé d'un attachement obligatoire à telle ou telle valeur. De plus, les aînés auront besoin de la connaissance expérimentale des jeunes. Ces derniers devront pouvoir participer directement et poser des questions. Cependant, il faudrait qu'il y ait assez de confiance entre les générations pour que les aînés puissent travailler sur les réponses. Ainsi, il est primordial à notre époque de ne pas sous-estimer la manière dont la culture est transmise des jeunes générations vers les aînés. Ce qui est en train de se produire dans les diasporas musulmanes est en fait une redéfinition par les jeunes générations de la signification même de la foi dans une forme plutôt individualisée, qui défie les définitions antérieures et tend à ignorer les différences entre religion et culture.

\section{Euro-islam : la renaissance de "l'honneur"}

Les Euro-Turcs et les Euro-musulmans en général, aliénés par le système et emportés vers une destinée dominée par l'Occident capitaliste, n'inventent plus leur avenir au niveau local. Ce qui les rend différents, c'est qu'ils restent attachés à leurs passés traditionnels, à leurs religions et leurs ethnicités. Re-fabriquer ou retrouver le passé permet de se retrouver soi-même sans être dépendant de critères transmis par d'autres ${ }^{(20)}$. Ceux qui font partie des diasporas savent que le passé leur appartient, d'où leur attachement à l'islam, à la culture, à l'authenticité, à l'ethnicité, au nationalisme et aux traditions. Ainsi, les Euro-Turcs peuvent former des réseaux de solidarité, barricades contre les agrégats les plus massifs du modernisme tels que le capitalisme, l'industrialisme, le racisme, la surveillance, l'égoïsme, l'isolement, l'insécurité, la structuration de l'étranger et le militarisme. La renaissance islamique 
émerge en tant que symptôme ou résultat d'un certain processus de structuration de l'étranger.

L'islam est plus ou moins considéré et représenté comme une menace aux modes de vie européens en Occident. Il est fréquemment souligné que le fondamentalisme islamique est la source des attitudes contemporaines de xénophobie, de racisme et de violence. Cependant, une des prémisses du présent travail est que la résurgence religieuse est un symptôme de maladies causées par des contraintes structurelles telles que le chômage, le racisme, la xénophobie, l'exclusion et parfois l'assimilation. Si mon hypothèse est exacte, alors, pour s'attaquer à ces contraintes, il est nécessaire de recourir à un discours sur la culture, l'identité, la religion, l'ethnicité, les traditions et le passé auprès des minorités en général et des groupes Il est évident que
les changements
technologiques ont
transformé les nouvelles
générations. Les jeunes
ont la possibilité
d'identités multiples
par voie électronique. d'immigrés en particulier. Cet acte politique est actuellement mis en place par des groupes externes. Selon Alistair MacIntyre, il y a deux types de politique : la politique de l'intérieur et la politique de ceux qui sont exclus ${ }^{(21)}$. Ceux de l'intérieur ont tendance à utiliser les institutions politiques légitimes (Parlement, partis politiques, média) pour atteindre leur but et ceux qui sont exclus utilisent la culture, l'ethnicité, la religion et la tradition pour poursuivre leurs objectifs.

Il faut souligner que MacIntyre ne positionne pas la culture dans l'espace privé ; elle est plutôt constitutive de l'espace public. Ainsi, la quête de l'identité, de l'authenticité et de la religiosité ne doit pas être réduite à une tentative d'essentialiser une soi-disant pureté. L'islam n'est plus une simple religion, mais aussi un mouvement politique contre l'hégémonie globale. À une époque d'insécurité, de pauvreté, d'exclusion, de discrimination et de violence, les miséreux de ce monde s'engagent pour la protection de leur "honneur", qui semble être la seule chose qui leur reste. Pour comprendre la signification grandissante de l'honneur, Akbar S. Ahmed attire notre attention sur l'effondrement de ce que Mohammad Ibn Khaldun ${ }^{(22)}$ a appelé "asabiyya", mot arabe qui fait référence à la loyauté du groupe, à la cohésion sociale ou à la solidarité. L'asabiyya lie les groupes entre eux à travers un langage, une culture, un code de comportements communs. Ahmed établit une corrélation négative directe entre l'asabiyya et la renaissance de l'honneur. L'écroulement de l'asabiyya à l'échelle mondiale incite les musulmans à redonner vie à l'honneur. Il avance l'idée que l'asabiyya s'écroule pour des raisons variées, à savoir "l'urbanisation massive, les changements démographiques dramatiques, l'explo- 
sion de la population, l'immigration massive vers l'Occident, la fracture entre riches et pauvres, la corruption étendue et la mauvaise gestion des dirigeants, le matérialisme rampant accompagné d'un manque de reconnaissance de l'importance de l'éducation, la crise identitaire et peut-être de manière plus significative, de nouvelles et souvent étran-

\section{Dans les régimes politiques étatiques ou libéraux, où l'individu est celui qui bénéficie de droits, la religion est perçue comme une orientation individuelle qui s'organise dans le cadre d'associations volontairement consenties.}

ges idées et images, à la fois séductrices et répugnantes, communiquées de manière instantanée à partir de l'Occident; des idées et des images qui défient les valeurs et coutumes traditionnelles ${ }^{(23) !}$.

L'effondrement de l'asabiyya implique aussi pour les musulmans l'échec de l'adl (justice), et de l'ihsan (compassion et équilibre). Le désordre mondial caractérisé par un manque d'asabiyya, d'adl et d'ihsan semble déclencher l'essentialisation de l'honneur par les musulmans. L'augmentation des crimes liés à l'honneur dans le contexte musulman illustre la manière dont l'honneur devient instrumentalisé et essentialisé. La popularité des crimes d'honneur parmi les Euro-musulmans permet à certaines élites politiques conservatrices en Occident de l'identifier comme un élément indispensable de l'islam. Or il faut souligner que les crimes d'honneur ne sont pas propres à la culture islamique : ils sont également visibles dans le monde judéo-chrétien. Les crimes d'honneur ont plutôt été structurellement contraints. Les traumatismes liés à la migration, à l'exclusion et à la pauvreté vécues par des migrants non éduqués, occupant des fonctions subalternes ou sans emploi, ont préparé un terreau propice aux actes de violence, aux crimes d'honneur et à la délinquance.

\section{L'institutionalisation de l'islam en Europe}

En opposition à l'individualisation de l'islam parmi les jeunes générations d'Euro-musulmans, un processus antithétique se produit simultanément : l'institutionalisation de l'islam en Europe. Différentes initiatives ont été prises jusquelà pour institutionaliser l'islam dans les minorités : l'Exécutif des musulmans de Belgique (1995), le Conseil de réflexion sur l'islam en France (CORIF, en 2003), des organismes nationaux aux Pays-Bas qui supervisent la construction de mosquées, l'emploi d'imams et l'approvisionnement en viande halal ${ }^{(24)}$, la tentative de la chancellière allemande Angela Merkel de réunir les musulmans à travers un 
sommet de l'Intégration qui s'est tenu en juillet 2006, ainsi que la conférence sur l'islam qui a eu lieu en septembre 2006. Mais ces tentatives d'organiser l'islam européen ont, jusqu'à présent, été inefficaces, à cause notamment des clivages nationaux, ethniques et doctrinaux qui divisent les populations musulmanes. Il faut également considérer les manières dont la construction de l'Union européenne pourrait influencer la forme et le contenu de l'expression islamique. La fortification des frontières européennes avec les pays voisins à travers le traité de Schengen (1985) renforce les frontières politiques et culturelles qui séparent l'Europe de ses voisins du Sud et de l'Est. La montée du discours sur le "choc des civilisations" a aussi contribué à approfondir les frontières entre les vies et les mondes des Européens et des non-Européens. En même temps, les questions sociales telles que la controverse sur la guerre du Golfe, le Soudan, l'Afghanistan et l'Iran, la publication des Versets sataniques en Grande-Bretagne, le meurtre du réalisateur néerlandais Théo Van Gogh aux Pays-Bas, le débat sur les caricatures au Danemark et l'intervention provocatrice du pape Benoît XVI concernant la nature "brutale" du prophète Mahomet, ont contribué à rapprocher les musulmans européens protestataires, provoquant des réactions hostiles de la part des Européens qui, pour la première fois, voyaient les musulmans immigrés en Europe comme une entité réunie. Tous ces événements ont fait naître un questionnement sur la signification de la présence collective musulmane en Europe et la radicalisation de l'identité islamique européenne. Il faut aussi noter que les récents débats dans les pays de l'UE démontrent que la forme européenne du sécularisme n'est pas encore adaptée pour recevoir l'islam, phénomène devenu très visible dans l'espace public récemment.

Dans son étude comparative de la Grande-Bretagne, de la France et de l'Allemagne durant la période 1973-2001, Koenig ${ }^{(25)}$ démontre que l'intégration publique des immigrés musulmans suit des schémas spécifiques formés par la logique légalement institutionalisée des politiques traditionnelles religieuses, qui elles-mêmes sont nées de la formation historique des États ou des nations. Dans ce cadre, un des facteurs cruciaux est le degré de l'institutionalisation de l'idée de l'individu dans chaque régime politique, puisque cela agit sur la définition même de "religion". Dans le régime politique corporatiste, où les droits sont attribués à des personnes morales, la religion est considérée comme une organisation formelle d'adhérents, ce qui lui confère une place dans le projet rationnel de l'État. Dans les régimes politiques étatiques ou libéraux, où l'individu est celui qui bénéficie de droits, la religion est perçue comme une orientation individuelle qui s'organise dans le cadre d'associations volontairement consenties. Koenig souligne qu'il n'est pas étonnant que les conflits nés de la quête de reconnaissance des musulmans en Allemagne se cristallisent autour de questions légales organisationnelles : pour preuve, le débat notoire sur la 
reconnaissance d'organisations islamiques en tant que personnes morales d'ordre public, un problème qui est secondaire en Grande-Bretagne par exemple. Un autre facteur crucial est le degré d'étatisme. Dans les États-nations plutôt orientés vers l'étatisme ou le corporatisme, tels que la France ou l'Allemagne, l'intégration des minorités musulmanes est coordonnée par l'État en tant que centre d'organisation, tandis que dans les régimes politiques libéraux, tels que la Grande-Bretagne, cette intégration se déroule comme une négociation avec la société civile, au niveau local. Un troisième facteur est la relation entre les symboles de l'identité nationale et ceux de la sécularisation : puisque les symboles universalistes de l'identité nationale sont connectés aux idéologies de sécularisme, comme par exemple la laïcité pour la France, les demandes de reconnaissance religieuse sont conçues comme des trangressions du clivage symbolique entre religion et sécularisme. À l'inverse, des régimes politiques où l'État-nation a été soutenu par la mobilisation collective religieuse ou confessionnelle, comme c'est le cas en Grande-Bretagne ou en Allemagne par exemple, les symboles religieux sont mieux accueillis.

Ireland défend l'idée que les groupes d'immigrés s'organisent politiquement selon des lignes ethnoculturelles et religieuses parce que les institutions de la société accueillante, à travers leurs politiques et leurs pratiques, ont nourri l'ethnicité. Ireland avance l'hypothèse selon laquelle les individus immigrés sont des sujets actifs et réfléchis qui adoptent des stratégies de participation politique en réponse aux réglementations des institutions de la société accueillante. Ireland explique ainsi la renaissance islamique comme le résultat de la manière dont les institutions de la société d'accueil traitent les communautés d'immigrés d'origine musulmane : "Ainsi, ils reçoivent l'islam qu'ils méritent, comme ils récoltent ce qu'ils sèment en termes de mobilisation politique des immigrés ${ }^{(26)}$." Rath et al. concluent dans leur étude ${ }^{(27)}$ que l'institutionalisation de l'islam est "davantage déterminée par les sociétés dans lesquelles les musulmans s'installent que par les musulmans eux-mêmes". De la même manière, Christophe Soper et Joel Fetzer ont révélé que les modèles de relation Église-État représentent des facteurs déterminants dans les différences de réception des pratiques religieuses musulmanes en France, en Allemagne et en Grande-Bretagne ${ }^{(28)}$. Les institutions ont tendance à avoir leur propre vie. Quand une religion est institutionalisée, elle a tendance à créer sa propre industrie, qui est composé de "courtiers religieux" qui agissent comme des tampons entre leur propre communauté religieuse et l'État. Les institutions ont besoin de leur propre clientèle pour survivre. La survie des institutions islamiques, par exemple, dépend de l'existence de sujets fidèles qui sont prêts à rester à l'intérieur des frontières de la communauté religieuse, sans ressentir le besoin de s'incorporer dans le courant dominant de la société. Ce processus, nommé "reminorisation des minorités" par Ian Rath ${ }^{(29)}$, fait que les immigrés ne 
sont pas perçus comme des membres à part entière de la société d'accueil, et qu'ils seront sans doute tolérés mais pas acceptés dans les positions-clés ${ }^{(30)}$. Ainsi l'institutionalisation de l'islam semble-t-elle contredire les processus d'individualisation.

\section{Conclusion}

Les discussions sur les Euro-Turcs se sont embrasées à l'époque où la Turquie a obtenu une perspective pour une pleine adhésion à l'Union européenne. Les termes de ces discussions prennent leur source dans les débats autour du 11 septembre, des bombes de Londres en 2005, de l'islam, du meurtre de Pim Fortuyn et de Théo Van Gogh aux Pays-Bas, de la crise des caricatures danoises, de la gaffe malheureuse du pape sur le prophète Mahomet... Entre-temps, les Euro-musulmans en général, et les Euro-Turcs en particulier, ont été largement visibles dans la sphère publique européenne, de manière à alimenter un ressentiment islamophobe. Cependant, il semblerait que le vrai choc ne soit pas entre les chrétiens et les musulmans, mais plutôt entre les "séculaires", si l'on peut dire, et les musulmans qui deviennent plus visibles dans l'espace public. Les démarches de la Turquie pour devenir un membre de l'UE nourrissent aussi des sentiments islamophobes, et ceci démontre que le sécularisme européen éclairé n'est pas encore prêt à recevoir les musulmans dans la sphère publique. Des personnalités politiques telles que Valérie Giscard d'Estaing et Helmut Schmitt ont récemment souligné avec force les racines chrétiennes de la civilisation européenne au risque d'endommager le dialogue entre l'UE et ses voisins immédiats au sud et au sudest. Les séculaires ont opté pour un discours religieux qui essaie d'utiliser la tendance culturelle et religieuse défensive qui prévaut actuellement en Europe. L'accélération de ce conflit entre les autochtones (locaux) et les allochtones (d'origine étrangère) a eu pour résultat la politisation de nombreux Euro-Turcs dans des pays comme l'Allemagne, la France, la Belgique et les Pays-Bas. Ils sont conduits à s'exprimer à travers les voies politiques légitimes plutôt qu'à travers la culture, l'ethnicité ou la religion. Il ne faudrait pas sous-estimer le défi actuel auquel devront faire face les pays européens concernant les tentatives officielles conservatrices d'institutionnaliser l'islam, qui vont certainement créer la re-minorisation des minorités ethniques.

\section{Remerciements}

Je souhaite exprimer ma gratitude à l'Académie turque des sciences (TÜBA) et au Fonds pour la Recherche de l'université Bilgi d'Istanbul pour leur soutien précieux dans la conduite de ma recherche.

Texte traduit de l'anglais par Angie Cotte. 


\section{Bibliographie}

- Ian Buruma, Murder in Amsterdam: Death of Theo van Gogh and the Limits of Tolerance, London, Atlantic Books, 2007.

- Barry Buzan, Ole Wrver and Jaap de Wilde, Security: a New Framework for Analysis, Boulder, Lynne Rienner, 1998.

- Roxanne L. Doty, "Immigration and the Politics of Security", Security Studies, vol. 8, n² 2-3, 2000, p. 71-93.

- Franck Düvell, "Crossing the Fringes of Europe: Transit Migration in the EU's Neighbourhood", Centre on Migration, Policy and Society, Working Paper 33, 2006.

- Frantz Fanon, The Wretched of the Earth, New York, Grove Press, 2005.

- Jef Huysmans, "The Question of the Limit: Desecuritization and the Aesthetics of Horror in Political Realism", Millenium: Journal of International Studies, vol. 27, n³, 1998, p. 569-589.

- Jef Huysmans, The Politics of Insecurity, London, Routledge, 2006.

- Krzysztof Rybinski, "Global Labour Market and its Limitations: Reasons and Effects of the Emergence of Homo Sapiens Globalus", Address of the Deputy President of the National Bank of Poland in the "Debate: WORKERS 2020 a vision of the labour market and the labour environment in the forthcoming decades", Gda sk, 10 June 2006. http://www.nbp.pl/en/publikacje/lectures/Rybinski_gdansk.pdf.

- Saskia Sassen, "A Universal Harm: Making Criminals of Migrants", OpenDemocracy, 20 August 2003. http://www.opendemocracy.net/debates/article-10-96-1444.jsp\#.

- Michael J. Shapiro, Violent Cartographies: Mapping Cultures of War, Minneapolis, Minn.; London: University of Minnesota Press, 1997.

- William Walters, "Security, Territory, Metagovernance: Critical Notes on Antiillegal Immigration Programmes in the European Union", Paper presented at Istanbul Bilgi University, 7 December 2006.

- Slavoj Zizek, "For a Lleftist Appropriation of the European Legacy", Journal of Political Ideologies, vol. 3, n ${ }^{\circ} 1$ (February), 1998, p. 63-78.

- Aristide R. Zolberg, "The Democratic Management of Cultural Differences: Building Inclusive Societies in Western Europe and North America", Occasional Paper 17, United Nations Developent Office, Human Development Report Office, 2004.

\section{Notes}

1. Pour des informations détaillées sur la recherche, se référer à Ayhan Kaya and Ferhat Kentel, Euro-Turks: A Bridge or a Breach between Turkey and the European Union? A Comparative Study of French-Turks and German-Turks, CEPS EU-Turkey Working Papers n ${ }^{\circ} 14$ (January), 2005. Cette recherche contient des interviews approfondies et des discussions en groupe autour de thématiques précises, ainsi que 1065 interviews structurées de quatre-vingt dix questions en allemand et 600 interviews en France. Ces entretiens, conduits par deux compagnies locales de sondage en Allemagne et en France, ont eu lieu entre décembre 2003 et janvier 2004 et concernaient des étudiants universitaires de langue turque qui parlaient couramment le français ou l'allemand. Les interviews étaient menées dans l'une des trois langues (turc, allemand et français) en fonction du choix de l'interviewé(e). Nous pouvons souligner que $20 \%$ des interviews en Allemagne se sont déroulées en allemand, et 30\% ayant lieu eu en France en français. L'équipe de recherche a mis en place un quota échantillon dans chaque pays; une attention particulière a été prêtée à la densité de la population d'origine turque, tant dans l'espace urbain que rural. Le quota échantillon couvrait les variables de l'âge, du sexe, de l'occupation et de la région afin de dégager une image représentative des Euro-Turcs. Une recherche identique s'opère actuellement en Belgique sur un échantillon de 400 interviews structurées ainsi que des interviews approfondies et des discussions en groupe sur des thématiques précises. La recherche sur les Néerlandais turcs, qui a eu lieu durant l'hiver 2007, n'est basée que sur des techniques d'analyse qualitative.

2. Şengül Kara, "Témoignages", colloque ELELE, ACSE, Palais du Luxembourg, Paris, 27 janvier 2007.

3. Voir Ayhan Kaya and Ferhat Kentel, Belgian-Turks: A Bridge or a Breach between Turkey and the European Union?, King Baudouin Foundation, Brussels, 2007 ; Ayhan Kaya, Islam, Migration and Integration: The Age of Securitization, London, Palgrave, 2009.

4. Michael Walzer, "Equality and Civil Society", in S. Chambers and W. Kymlicka (eds.), Alternative Conceptions of Civil Society, Princeton, Princeton University Press, p. 40-41.

5. Dirk Jacobs et Jean Tillie, "Introduction: Social Capital and Political Integration of Migrants", Journal of Ethnic and Migration Studies, vol. 30, n³, 2004, p. 421. 
6. Will Kymlicka et Wayne Norman (eds.), Citizenship in Diverse Societies, Oxford, Oxford University Press, 2000 , p. 39.

7. Interview personnelle, Utrecht, 28 mars 2007.

8. Nadia Fadil, "The Political Mobilization of Muslim Minorities in the West: a Gender (Un)friendly Project?", in Joseph Suad (ed.), Encyclopedia of Women and Islamic Cultures, vol. 2, Leiden, Brill, 2005, p. 293-295.

9. Peter Mandaville, Transnational Muslim Politics: Reimagining the Umma, London, Routledge, 2001, p. 141.

10. Jorgen Nielsen, "Muslims in Britain: Searching for an Identity?", New Community, vol. 13, n³, 1987, p. 392.

11. Mette Andersson, "Ethnic Entrepreneurs: Identity Politics among Pakistani Students", in H. G. Sicakkan and Y. G. Lithman (eds.), What Happens When a Society is Diverse: Exploring Multidimensional Identities, Lewiston, Edwin Mellen Press, 2006, p. 45.

12. Nous pouvons citer les forums suivants parmi les plus populaires : http://www.islamisohbet.net; http://www.nurluyuz.com; http://www.islamiweb.net; http://toplist.ihya.org; http://www.islamilist.com, http://www.islamisanat.net.

13. John Brecher, Brown Childs and Jill Cutler, Global Visions: Beyond the New World Order, Boston, South End Press, 1993.

14. Peter Mandaville, op. cit., p. 160.

15. Arjun Appadurai, Modernity at Large: Cultural Dimensions of Globalisation, Minneapolis, University of Minnesota Press, 1996, p. 195.

16. Benjamin R. Barber, "More Democracy, More Revolution", The Nation, 26 October 1998, p.126.

17. Diane Crane, Invisible colleges: Diffusion of Knowledge in Scientific Communities, Chicago, University of Chicago Press, 1972.

18. Jabari Mahiri, "Pop Culture Pedagogy and the End(s) of School", Journal of Adolescent $\mho$ Adult Literacy 44/4 (December), 2000, p. 382-385.

19. Margaret Mead, Culture and Commitment: A Study of the Generation Gap, New York, Doubleday, 1970.

20. Keya Ganguly, "Migrant Identities: Personal Memory and the Construction of Selfhood," Cultural Studies, vol. 6, $\mathrm{n}^{\circ} 1$ (January), 1992, p. 40.

21. Alistair MacIntyre, Against the Self-Images of the Age: Essays on Ideology, New York, Schoken Books, 1971.

22. Mohammad Ibn Khaldun, The Muqaddimah: An Introduction to History, N.J. Dawood (ed.), Franz Rosenthal (trans.), Princeton, Princeton University Press, 1969.

23. Akbar S. Ahmed, Islam under Siege: Living Dangerously in a Post-Honor World, Cambridge, U.K., Polity Press, 2003, p. 81.

24. Jocelyne Cesari, "Muslim Minorities in Europe: The Silent Revolution", in John Esposito and François Burgat (eds.), Modernizing Islam: Religion in the Public Sphere in the Middle East and in Europe, Rutgers University Press, 2003, p. 251-269.

25. Matthias Koenig, "The Public Incorporation of Muslim Migrants in Western Europe. A Comparative Perspective", in Religion and Diversity in International Focus: Research and Policy Issues, chair Paul Bradamat, John Biles, and Humera Ibrahim, 8th International Metropolis Confederence, Vienna, 2003. L'étude de Koenig rejoint trois autres études conduites par Patrick R. Ireland (2000), Jan Rath et al. (2001) et Soper et Fetzer (2003).

26. Patrick R. Ireland, "Reaping What They Sow: Institutions and Immigrant Political Participation in Western Europe", in R. Koopmans and P. Statham (eds.), Challenging Immigration and Ethnic Relations Politics, Oxford, Oxford University Press, 2000, p. 269.

27. Jan Rath et al, Western Europe and its Islam, Leiden, Brill, 2001.

28. Christopher Soper and Joel S. Fetzer, "Explaining the Accommodation of Muslim Religious Practices in France, Britain, and Germany", French Politics n'1, 2003, p. 39-59.

29. Jan Rath, "The Ideological Representation of Migrant Workers in Europe: A Matter of Racialisation?", J. SolomosveJ. Wrench (der.), Racism and Migration in Western Europe, Oxford, Berg Publishers, 2003, p. 215-232.

30. Pontus Odmalm, Migration Policies and Political Participation: Inclusion or Intrusion in Western Europe?, Hampshire, Palgrave MacMillan, 2005, p. 47. 